\title{
Investigation of piled behaviour due to an adjacent excavation: 3D numerical modelling
}

\author{
Zameer Ahmed Channar ${ }^{1}$, Abdullah Saand ${ }^{2}$, Zeeshan Ahmed Sahito ${ }^{3}$ \\ ${ }^{1}$ Department of Civil Engineering, \\ Quaid-e-Awam University of Engineering, Science \& Technology, Nawabshah, Pakistan, \\ 'zameer.channar19@gmail.com, ${ }^{2}$ abdullah@quest.edu.pk, ${ }^{3}$ zeeshansahito5@gmail.com
}

\begin{abstract}
In congested cities, excavations are unavoidably constructed adjacent to high rising building supported by piled raft foundations which reduces differential settlements in the buildings. Since the excavations inevitably induce soil movement and stress changes in the ground, it may cause differential settlements to nearby piled raft foundation. In this numerical study, a 3D coupled consolidation numerical analysis (using a hypoplastic model, which considers strain dependent and path-dependent soil stiffness) was conducted to investigate a $(2 \times 2)$ piled raft responses to an adjacent $25-\mathrm{m}$ deep excavation in saturated clay. The computed results have revealed that the rate of piled raft settlement increased significantly beyond excavation stage $\mathrm{h} / \mathrm{He}=0.5$. This is because of the degradation of stiffness of clay with strain due to excavation-induced stress release. Differential settlement (i.e. tilting) was induced in the piled raft due to non-uniform stress release.

Owing to separation of the raft from the ground due excavation, some of the working load was transferred to the four piles. The maximum positive bending moment was 200 $\mathrm{kNm}$ at $\mathrm{Z} / \mathrm{Lp}=0.67$. However, no any bending moment was induced in both the piles at the toes.
\end{abstract}

Key words: Multipropped excavation; pile raft; tilting; load transfer

\section{INTRODUCTION}

Due to shortage of lands, high-rise buildings are preferred to meet the development and economic growth in major cities. The construction of high rise buildings often requires deep foundations such as single pile and pile group when the underlying soil and rock strata do not have sufficient bearing capacity. Owing to the inherent lack of surface space in congested urban areas, deep excavation for basements and cut-and-cover tunnels are inevitably constructed adjacent to existing pile foundations. In urban areas many high buildings are supported by piled rafts because the use of piles to reduce raft settlements and differential settlements can lead to considerable economy without compromising the safety and performance of the foundation [20]. Since the construction of excavations inevitably induces soil movement and stress changes in the ground, it may cause additional settlement and differential settlements to nearby existing piled foundations. To understand the excavation-pile interaction mechanism, many researchers have conducted field monitoring studies and centrifuge model tests [1-14]. Finno et al. [14] and Goh et al. [1] presented field studies in granular and alluvium soil, respectively, reporting lateral pile movement and induced bending moment due to excavation. In these studies, the pile depths were much deeper than the excavation depth. Leung et al., [4-5] performed centrifuge tests in dry, dense Toyoura sand to investigate the effects of unpropped excavation on an adjacent single pile and pile group, respectively. They found that pile head conditions and their distance from walls had a significant effect on the induced bending moment and lateral pile movements. In these studies, piles were treated as end bearing piles, and excavation-induced settlement and tilting were ignored. Liyanapathirana and Nishanthan [13] and Poulos and Chen [17] developed design charts for excavation-induced pile bending moments and lateral deflection using a finite-element method and two-stage analysis, respectively. Field studies reported by Korff et al., [18] showed that buildings supported by pile foundations were damaged by excavation-induced settlement and tilting. Based on above mentioned issues, this study investigate effects of excavation-induced stress release on an adjacent $(2 \times 2)$ piled raft. The settlement and load transfer mechanism of the piled raft was explored.

\section{THREE-DIMENSIONAL COUPLED CONSOLIDATION ANALYSIS}

Discarded To gain new insights into a $(2 \times 2)$ piled raft responses to an adjacent excavation in saturated clay, this study conducts a three-dimensional coupled consolidation numerical study. The final depth of the excavation (He) was taken as $25 \mathrm{~m}$. The excavation was performed in different stages (i.e. $\mathrm{h}=2,5,8,11,14,17,20,23$ and $25 \mathrm{~m}$ ) to investigate the different excavation depths. Fig.1(a) shows the elevation view of the configuration of numerical simulation in which a multipropped excavation was carried out adjacent to 
a $(2 \times 2)$ piled raft. All four piles were rigidly connected by a 1.2 thick raft resting on the ground. The size of the raft is $5 \mathrm{~m}$ by $5 \mathrm{~m}$. The embedded length (Lp) and diameter (dp) of the pile were $18 \mathrm{~m}$ and $0.8 \mathrm{~m}$, respectively. The clear distance between diaphragm wall and the front row of piles was $3.0 \mathrm{~m}$. The excavation was supported by $0.6 \mathrm{~m}$ thick diaphragm wall. The ratio of wall penetration depth to excavation depth is typically $0.5-0.2$ in engineering practice [15-16], and thus a value of 0.5 was adopted in this study. The retaining wall was supported by seven levels of props. The props were modelled as soft with axial rigidity of $81 \times 103 \mathrm{kNm}$ [15]. Horizontal spacing of props was $10 \mathrm{~m}$. Fig.1(b) illustrates the plan view of the configuration of the numerical simulation. The length of the excavation is $12 \mathrm{~m}$. Due to symmetry, only half of the excavation was simulated. A monitoring section was selected at the transverse centreline of the excavation.

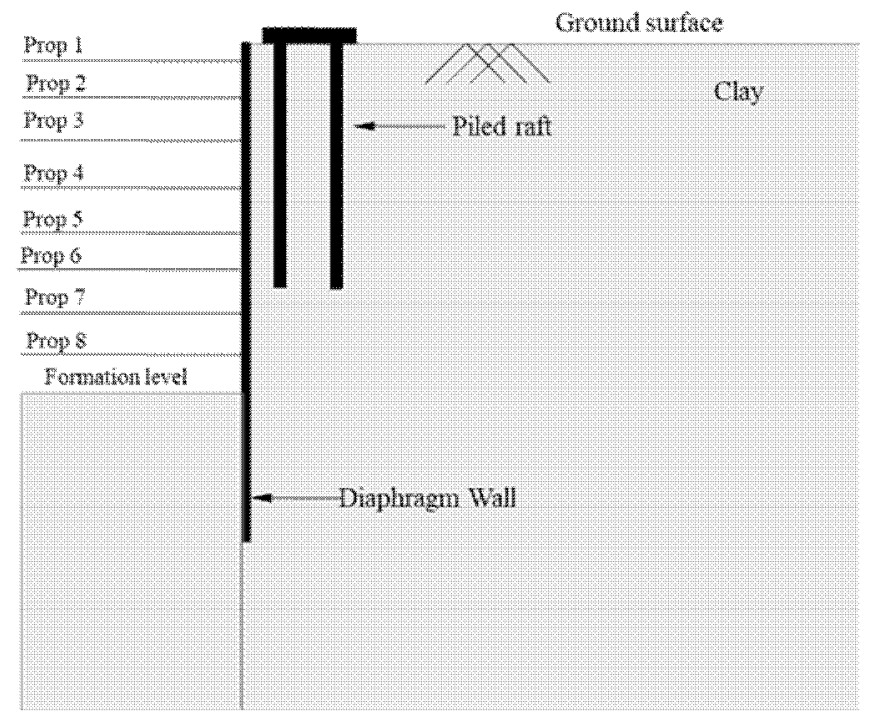

(a)

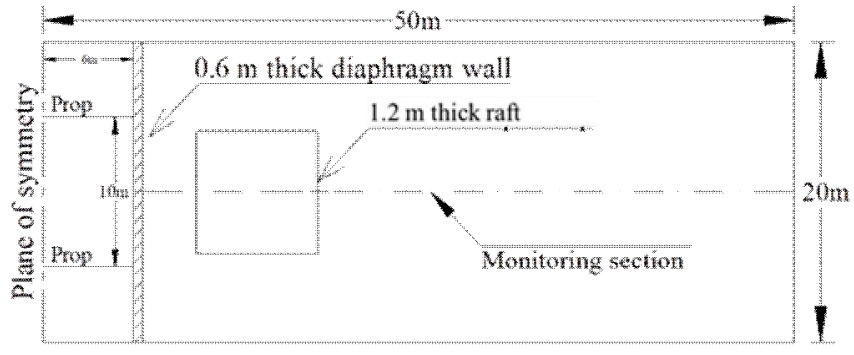

(b)

Fig.1. Configuration numerical run (a) elevation view (b) plan view

\subsection{FINITE ELEMENT MESH AND BOUNDARY CONDITIONS}

Fig. 2 shows an isometric view of a finite element mesh used for analysing the excavation problem. The size of the mesh for each numerical runs is $50 \mathrm{~m} \times 20 \mathrm{~m} \times 40 \mathrm{~m}$. These dimensions were sufficiently large to minimise boundary effects in the numerical simulation as further increment in the dimensions of the finite element mesh did not lead to any change in the computed results. Regarding the element size in the mesh, it is found that further halving the adopted mesh size only leads to a change of computed results of no more than $0.2 \%$, suggesting the mesh is sufficiently fine. Eight-noded hexahedral brick elements were used to model the soil, the pile and the diaphragm wall, while two-noded truss elements were adopted to model the props. Roller and pin supports were applied to the vertical sides and the base of the mesh, respectively. Therefore, movements normal to the vertical boundaries and in all directions of the base were restrained. The piles-soil and wall-soil interface was modelled as zero thickness by using duplicate nodes. The interface was modelled by the Coulomb friction law, in which the interface friction coefficient $(\mu)$ and limiting displacement $\left(\gamma_{\text {lim }}\right)$ are required as input parameters. A limiting shear displacement of $5 \mathrm{~mm}$ was assumed to achieve full mobilization of the interface friction equal to $\mu \times p^{\prime}$, where $\mathrm{p}^{\prime}$ is the normal effective stress between two contact surfaces. The excavation process was simulated by deactivating soil elements inside excavation zone. In the meantime, the truss elements representing the props were activated

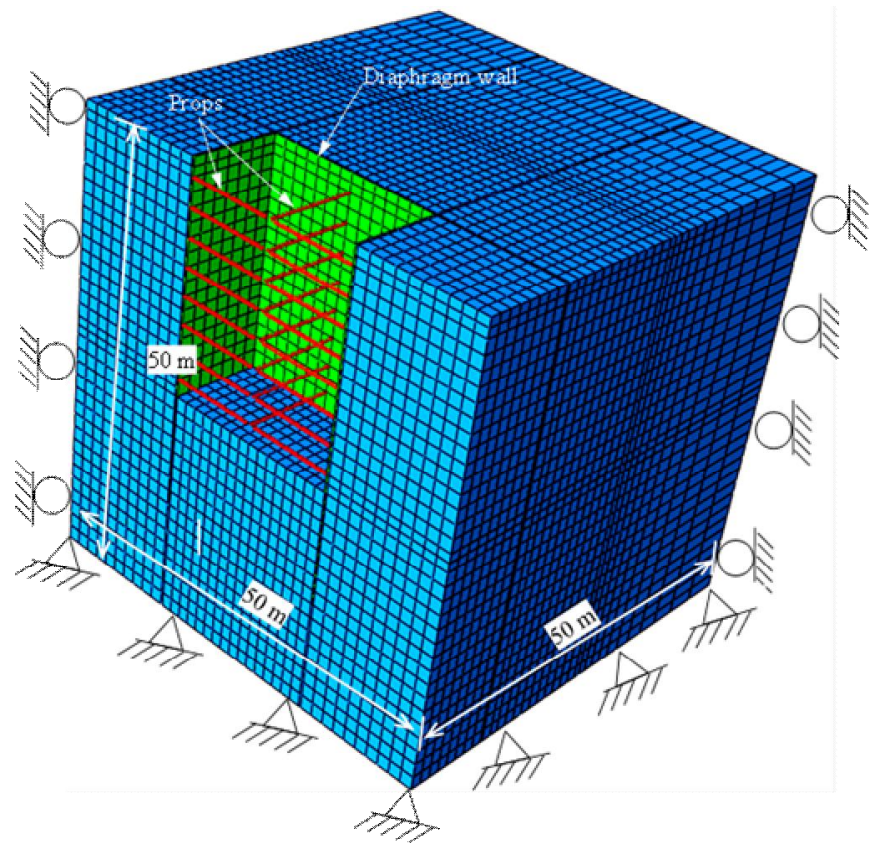

Fig.2. Finite element mesh and boundary conditions

\subsection{CONSTITUTIVE MODEL AND MODEL PARAMETERS USED IN FINITE ELEMENT ANALYSIS}

\subsection{CONSTITUTIVE MODEL}

It is well recognized that to properly capture the ground deformation induced by unloading, it is vital to take into account the dramatic increase in soil stiffness upon reversal of stress path in the constitutive soil model. For this reason, an advanced hypoplastic clay model [9] coupled with the intergranular strain concept [10] was adopted in this numerical investigation to capture the nonlinear path-dependent soil stiffness at small strains. The constitutive model has been implemented in the commercial finite element software package Abaqus through a user-defined subroutine. The basic hypoplastic model was developed to capture the nonlinear behaviour (upon monotonic loading at medium-to large-strain levels) of granular materials [9, 10]. 
The model allows for capturing different stiffness in loading, unloading, softening, hardening and the change of volume in shearing (i.e. dilation and compression). The current stiffness depends upon not only stress path but also recent stress history. In case of Hypoplastic clay model, the standard yield surface is replaced by boundary state surface. Hypoplastic model is generally described by a single nonlinear tensorial equation yielding the stress state $\dot{T}$ as a function of stretching rate $\mathrm{D}$ [9]. The general stress-strain relation is as follows:

$\dot{\mathrm{T}}=f \mathrm{~s} \mathrm{~L}: \mathrm{D}+f \mathrm{~s} f \mathrm{a} \mathrm{N}\|\mathrm{D}\|$

where $\mathrm{L}$ and $\mathrm{N}$ are fourth and second-order constitutive tensors, respectively. $f$ s and $f$ a are scalar factors expressing the influence of barotropy and pyknotropy.

The basic model consists of five parameters $\left(\mathrm{N}, \lambda^{*}, \kappa^{*}, \varphi c\right.$ and r). The parameters $\mathrm{N}$ and $\lambda^{*}$ define the position and the slope of the isotropic normal compression line in the $\ln (1+\mathrm{e})$ versus In p' plane. e is the void ratio, and p' is the mean effective stress. The parameter $\kappa^{*}$ defines the slope of the isotropic unloading line in the same plane. $\varphi c$ is the critical state friction angle, and the parameter $r$ controls the large strain shear modulus. To account for the strain dependency and path dependency of the soil stiffness (at small strains), Niemunis and Herle [22] further improved the basic hypoplastic model by incorporating the concept of intergranular strain. The intergranular strain concept requires five additional parameters $\left(\mathrm{R}, \beta, \chi, \mathrm{m}_{\mathrm{T}}\right.$ and $\left.\mathrm{m}_{\mathrm{R}}\right): \mathrm{R}$ controls the size of the elastic range, and $\beta$ and $\chi$ control the rate of stiffness degradation. The parameters $m_{T}$ and $m_{R}$ control the initial shear modulus upon $180^{\circ}$ and $90^{\circ}$ strain path reversal, respectively. In this hypothesised study, the parameters for silty clay were adopted Mašín et al., [9]. All the model parameters for silty clay reported by Wang et al., [25] are summarised in Table 1. The coefficient of lateral earth pressure at rest, Ko is estimated by Mayne and Kulhawy's [24] equation $\mathrm{Ko}=(1-\sin \varphi)(\mathrm{OCR})^{\sin \varphi}$.

\section{Table 1 Model parameters of kaolin clay adopted in the} parametric study

\begin{tabular}{lc}
\hline \multicolumn{1}{c}{ Description } & $\begin{array}{c}\text { Paramete } \\
\mathrm{r}\end{array}$ \\
\hline $\begin{array}{l}\text { Effective angle of shearing resistance at } \\
\text { critical state: } \phi^{\prime}\end{array}$ & $22^{\circ}$ \\
$\begin{array}{l}\text { Parameter controlling the slope of the } \\
\text { isotropic normal compression line in the } \ln (1\end{array}$ & 0.11 \\
$+\mathrm{e})$ versus lnp plane, $\lambda^{*}$ & \\
$\begin{array}{l}\text { Parameter controlling the slope of the } \\
\text { isotropic normal compression line in the } \ln (1\end{array}$ & 0.026 \\
+ e) versus lnp plane, $\kappa^{*}$ & \\
$\begin{array}{l}\text { Parameter controlling the position of the } \\
\text { isotropic normal compression line in the }\end{array}$ & 1.36 \\
ln $(1+\mathrm{e})-\ln$ plane, $\mathrm{N}$ \\
$\begin{array}{l}\text { Parameter controlling the shear stiffness at } \\
\text { medium- to large- strain levels, } \mathrm{r}\end{array}$ \\
$\begin{array}{l}\text { Parameter controlling initial shear modulus } \\
\text { upon } 180^{\circ} \text { strain path reversal, } \mathrm{m}_{\mathrm{R}}\end{array}$ \\
$\begin{array}{l}\text { Parameter controlling initial shear modulus } \\
\quad\end{array}$ & 11
\end{tabular}

upon $90^{\circ}$ strain path reversal, $\mathrm{m}_{\mathrm{T}}$

\begin{tabular}{lc}
$\begin{array}{l}\text { Size of elastic range, } \mathrm{R} \\
\text { Parameter controlling the rate of degradation } \\
\text { of the stiffness with strain, } \beta_{\mathrm{r}}\end{array}$ & $1 \times 10^{-5}$ \\
$\begin{array}{l}\text { Parameter controlling degradation rate of } \\
\text { stiffness with strain, } \chi\end{array}$ & 0.1 \\
$\begin{array}{l}\text { Initial void ratio, e } \\
\text { Dry density }\left(\mathrm{kg} / \mathrm{m}^{3}\right)\end{array}$ & 0.7 \\
Coefficient of permeability, $\mathrm{k}(\mathrm{m} / \mathrm{s})$ & 1136 \\
\hline
\end{tabular}

The concrete pile, the diaphragm wall and the props were assumed to be linear elastic with Young's modulus of $35 \mathrm{GPa}$ and Poisson's ratio of 0.25 . The thickness of the wall was taken as $0.60 \mathrm{~m}$. The unit weight of concrete was taken as 24 $\mathrm{kN} / \mathrm{m}^{3}$.

\subsection{NUMERICAL MODELLING PROCEDURE}

The numerical analysis modelling procedure for a typical case is summarized as follows:

Step 1: Set up the initial boundary and initial effective stress conditions

Step2: Activate the piled raft elements.

Step 3: Apply the working load on the raft.

Step 4: Activate the brick elements representing the diaphragm wall.

Step 5: Staged multi-propped excavation is simulated. After excavating to $3 \mathrm{~m}$ depth, the first level of props is installed at $1 \mathrm{~m}$ below the ground surface.

Step 6: Repeat step 5 to excavate the next stages and install props until the last stage of excavation (i.e., $\mathrm{He}=25 \mathrm{~m}$ ) is completed.

\section{RESULTS AND DISCUSSION}

\subsection{INDUCED PILED RAFT SETTLEMENT DURING EXCAVATION}

The Fig. 3 shows the incremental settlement $\left(S_{p}\right)$ of the piled raft during different excavation stages. The different excavation stages $(h)$ are taken as $2,5,8,11,14,17,20,23$ and $25 \mathrm{~m}$ (i.e. $h / H_{e}=0.08,0.20,0.32,0.44,0.56,0.68,0.80$, 0.92 and 1.00). $S_{p}$ and $y$ are normalised by the pile diameter $\left(d_{p}\right)$ and the final excavation depth $\left(H_{e}\right)$, respectively. The measured induced single pile settlement due to excavation in centrifuge modelling reported by $\mathrm{Ng}$ et al., 2017 [6] and computed excavation-induced settlement of a single pile reported by Soomro et al., 2017a [15] and excavation-induced settlement of a elevated pile group reported by Soomro et al., $2017 \mathrm{~b}$ in are also shown in the figure for comparison. The centrifuge test was carried out to investigate the effects of a multipropped deep excavation (final depth of excavation $=8 \mathrm{~m}$ in prototype) in-flight on the behaviour of single pile (diameter of the pile $=1.25 \mathrm{~m}$ in prototype) in dry Toyoura sand (i.e. $D_{r}=70 \%$ ). It can be seen from the figure that the 
excavation-induced piled raft settlement increase linearly till excavation reaches at $h / H_{e}=0.5$. As the excavation stages reaches at $h / H_{e}=0.5$, the rate of piled raft settlement increased significantly. This is because of two reasons. Firstly, the piled raft is subjected to larger shear strain due to excavation-induced stress release as the excavation depth increases. Second reason is the degradation of stiffness of sand with strain due to excavation-induced stress release. In this study, the ground (clay) is modelled using an advanced constitutive soil model (i.e. hypoplastic model) which is capable to capture small-strain stiffness. The deeper excavation depth induced large shear strain causing significant of stiffness degradation near the diaphragm wall. When the toes of each pile are subjected to stress release due to excavation at deeper depth, the end-bearing of the piles decreased. Hence, the piled raft mobilised shaft resistance substantially by settling relative to the surrounding soil. Similar settlement characteristics of a single pile due to excavation observed from the centrifuge test and the computed results. However, induced settlements of the single pile and elevated pile group were smaller than that of the piled raft after excavation. The total settlement of the pile (including settlement due to working load and excavation) was $68 \mathrm{~mm}$ (i.e., $8.5 \%$ pile diameter). This conclusion might not be applicable to scenarios in which the ground conditions are different from those adopted in this study.

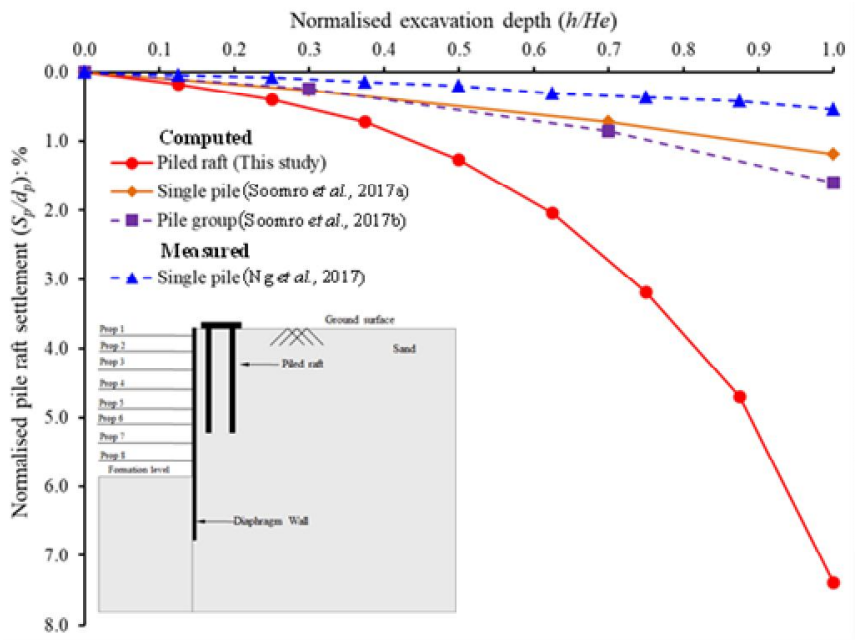

Fig: 3. Piled raft settlement during excavation

\subsection{INDUCED RAFT TILTING DURING EXCAVATION}

The excavation was carried out on one side of the piled raft. Since excavation is a stress release process, the piles closets to the excavation would settle higher than those farthest from the excavation. Hence differential settlement is induced in the piled raft. Usually, the differential settlement is expressed in term of tilting. The tilting is defined as the ratio of differential settlement between two corners of the raft to the distance between the two corners. Fig. 4 illustrates the induced tilting due to different excavation stages. For comparison, computed excavation-induced tilting of an elevated pile group reported by Soomro et al., 2017b is included in the figure. It can be seen from the figure that the tilting of the raft increases non-linearly with excavation stages. The rate of the tilting increases as the excavation goes deeper. This is because the closest piles are subjected to higher stress release than that of farthest piles on the piled raft. Similar settlement characteristics of an elevated pile group due to excavation observed from the computed results. However, induced tilting of elevated pile group was smaller than that of the piled raft after excavation. The maximum tilting of $0.34 \%$ was induced in the piled raft after completion of the excavation. The maximum value of induced tilting exceeds the allowable limit of tilting, according to the Singapore Building Code, at $0.1 \%$ (LTA 2010). The induced tilting resulted in load transfer not only within each pile but also among the piles in the piled raft system (discussed in section 3.3). No longitudinal tilting of pile cap was observed because of same stress release along longitudinal direction of the excavation.

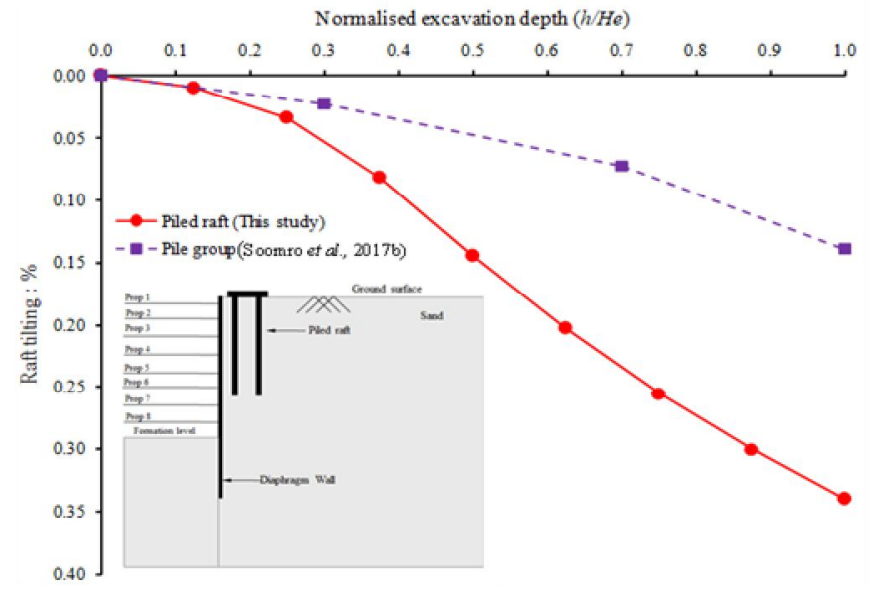

Fig: 4. Raft tilting during excavation

\subsection{LOAD SHARING BETWEEN RAFT AND PILES DURING EXCAVATION}

Fig. 5 shows the change in load sharing by the raft during excavation. It can be seen that before excavation (after application of working load), about $6.0 \%$ of the working load (i.e. $7.67 \mathrm{MN}$ ) was carried by the raft and rest of the load was transferred to the four piles equally.

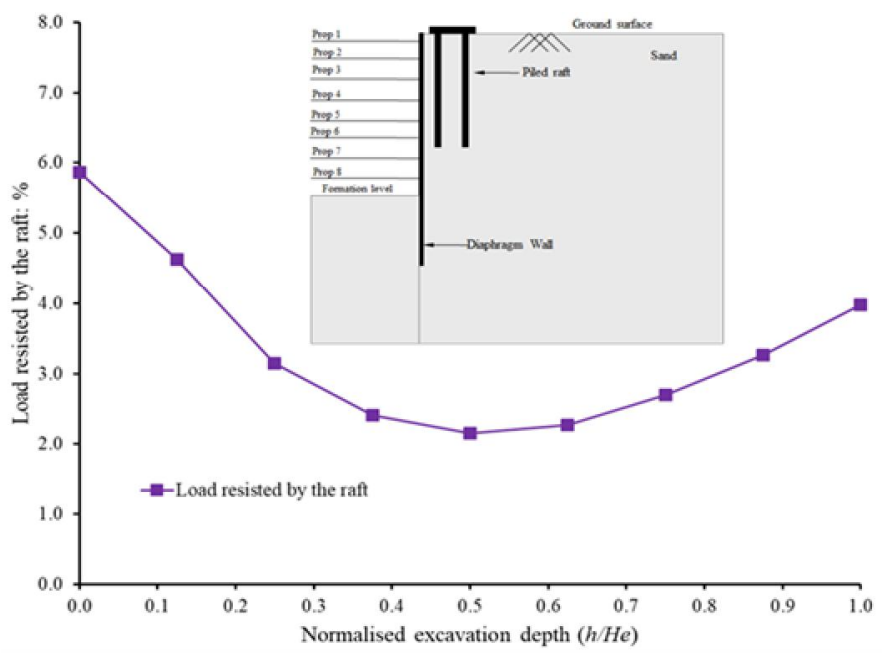

Fig. 3. Load penetration curve of existing subgrade 
It can be seen from the figure that the load taken by the raft kept decreasing till excavation reaches at half of final excavation depth $(\mathrm{h} / \mathrm{He}=0.5)$. This suggested that some of the working load was transferred to the four piles and the piled raft system behaves as elevated pile group (in which the pile cap is raised above the ground) after excavation. This can be attributed to separation of the raft and the ground because of induced larger ground surface settlement and lesser piled raft settlement. As a result of the gap between the raft and the piles, the effective vertical stress decreased significantly on completion of the excavation. However, as excavation proceeds beyond $\mathrm{h} / \mathrm{He}=0.5$, the load taken by the raft kept increasing till completion of the excavation. This implies that the load is re-transferred to the raft. This is because the deeper excavation led to substantial settlement in the raft but less ground surface settlement. The load carried by the raft reduced to $2 \%$ at excavation stage $\mathrm{h} / \mathrm{He}=0.5$ and after that increased to $4 \%$ on completion of the excavation.

\subsection{LOAD SHARING BETWEEN RAFT AND PILES DURING EXCAVATION}

Fig. 6 shows the axial force distribution with depth below ground surface $\mathrm{z}$ (normalized by pile length $\mathrm{L}_{\mathrm{p}}$ ) along piles $\mathrm{P} 1$ and $\mathrm{P} 2$ before and excavation.

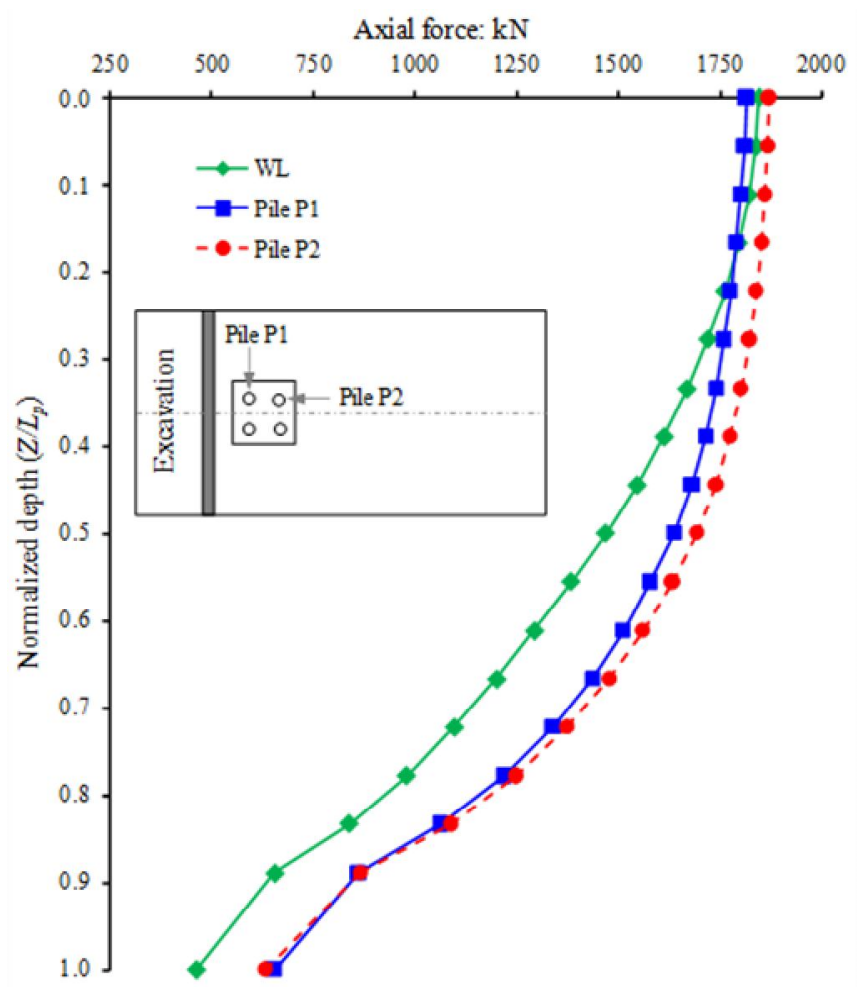

Fig. 6. Changes in axial load distribution along pile length after excavation

Before excavation, it can be deduced that about $6.0 \%$ of the applied working load (i.e. $7.82 \mathrm{MN}$ ) was taken by the raft and the remainder transferred to piles. Furthermore, $71 \%$ of the load transferred to each pile (i.e. $1650 \mathrm{kN}$ ) was resisted by the shaft resistance of the pile, while the remainder was carried by the end-bearing resistance in each case. It can be seen that the head load carried by pile P1 and P2 was increased slightly on completion of the excavation. As discussed, load taken by the raft reduced during excavation. To support constant applied load, the load transferred to pile heads. Owing to the excavation-induced stress reduction, the axial load increased along the entire length of the both piles. After completion of excavation, the maximum increment in the axial force $(50 \%$ of that at working load) was observed at $\mathrm{Z} / \mathrm{Lp}=0.58$. A closer inspection of axial load distribution after the excavation revealed that the shaft resistance along the upper portion of pile $\mathrm{P} 1(0 \leq \mathrm{Z} / \mathrm{Lp} \leq 0.43)$ became zero. This is attributed to reduction of excavation-induced normal stress to pile shaft. As a result of this the load borne by the upper portion transferred to the lower part and the pile toe (i.e. downward load transfer mechanism). This led in further mobilization of the shaft resistance at the lower portion of pile P1 and end-bearing resistance of the pile by means of settlement. To maintain vertical equilibrium of the piled raft, the soil surrounding the lower part of the pile (Z/Lp>0.45) resisted its settlement by mobilising positive skin friction (PSF) at the pile-soil interface and end-bearing resistance at the toe of the pile. The end-bearing of both the piles increased to $41 \%$ on completion of excavation.

\subsection{LOAD SHARING BETWEEN RAFT AND PILES DURING EXCAVATION}

Fig. 7 illustrates the induced bending moment along the pile $\mathrm{P} 1$ and P2 after excavation. A positive bending moment means that tensile stress was induced along the pile shaft facing the excavation. It can be seen that substantial negative bending moment (i.e. $250 \mathrm{kNm}$ ) was induced at $/$ near the heads of piles $\mathrm{P} 1$ and $\mathrm{P} 2$. This is because the lateral movement of the pile is restrained due to rigid connection with the pile cap. To counter-balance the negative moment at the pile head, a positive bending moment was induced in both piles. This is attributed to lateral soil movement towards excavation as a result of stress release (discussed in section 3.6). The maximum positive bending moment was $200 \mathrm{kNm}$ at $\mathrm{Z} / \mathrm{Lp}=0.67$. Compared the induced bending moment in the pile $\mathrm{P} 1$ on completion of the excavation, the pile $\mathrm{P} 2$ is subjected smaller bending moment along the length of the pile. Since pile toes are free to move, no any bending moment was induced in both the piles at the toes. 


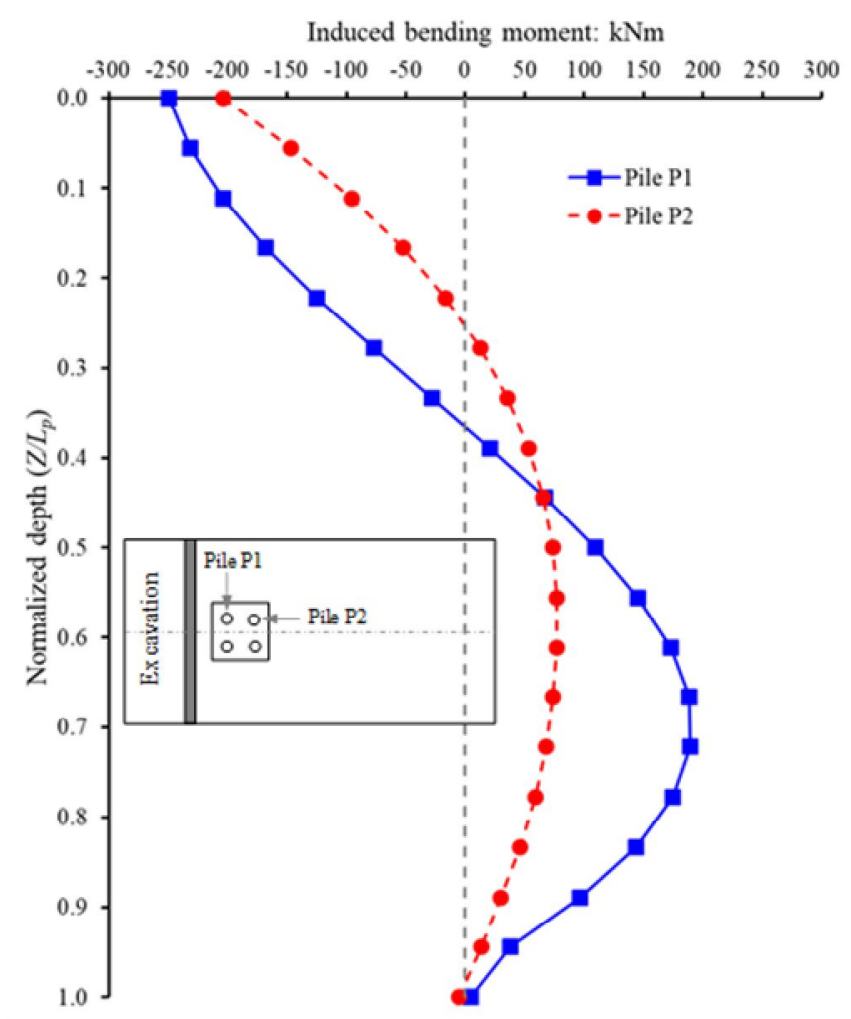

Fig: 7. Induced bending moment in piles $\mathrm{P} 1$ and $\mathrm{P} 2$

\subsection{COMPUTED GROUND DEFORMATION MECHANISM AND DEVIATORIC STRAIN AFTER EXCAVATION}

Fig. 8 shows the excavation-induced soil displacement in the ground. In addition, excavation-induced shear strain contours are also superimposed in each figure. It can be illustrated from the figures that soil on retained side displaced towards excavation whereas the soil underneath the excavation side heaved in distinctive log spiral-typed sliding wedge. A similar pattern in Kaolin clay was observed from PIV results in centrifuge test by Hong and $\mathrm{Ng}$ (2013). It can also be observed that deviatoric strain developed around excavation is within $6.5 \%$. A similar pattern and magnitude of excavation-induced shear strain were calculated from measured centrifuge test in Kaolin clay (Lam, 2010). This indicates that the finite element analysis results are appropriate to analyse excavation pile interaction problem. It can be seen from the figure that soil displacements around the excavation tend to manifest at the surface in a shape of settlement trough. The induced ground movement and deviatoric strain contours caused settlement and tilting of the raft, load re-distribution $\mathrm{s}$ and bending moment in piles.

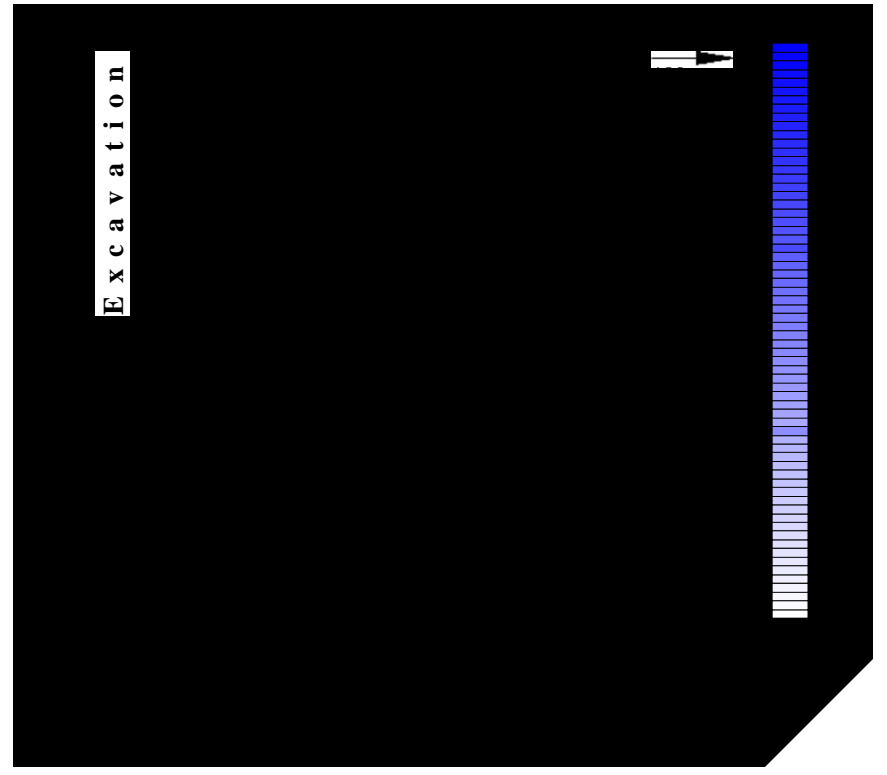

Fig.8. Induced ground movement and deviatoric strain after excavation

\section{SUMMARY AND CONCLUSIONS}

This study reports a 3D coupled consolidation numerical analysis (using a hypoplastic model, which considers strain dependent and path-dependent soil stiffness) investigating piled raft responses to an adjacent excavation in saturated clay. Based on the ground conditions and geometries, the following conclusions can be drawn:

(a) The excavation-induced piled raft settlement increase linearly till excavation reaches at $\mathrm{h} / \mathrm{He}=0.5$. However, the rate of piled raft settlement increased significantly beyond excavation stage $h / \mathrm{He}=0.5$. This is because of the degradation of stiffness of sand with strain due to excavation-induced stress release. The total settlement of the pile (including settlement due to working load and excavation) was $68 \mathrm{~mm}$ (i.e., $8.5 \%$ pile diameter).

(b) The piled raft is subjected to non-uniform stress release due to excavation. The piles closets to the excavation would settle higher than those farthest from the excavation. Hence differential settlement (i.e. tilting) is induced in the piled raft. The maximum tilting of $0.34 \%$ was induced in the piled raft after completion of the excavation. The maximum value of induced tilting exceeds the allowable limit of tilting, according to the Singapore Building Code, at $0.1 \%$ (LTA 2010). The induced tilting resulted in load transfer not only within each pile but also among the piles in the piled raft system.

(c) The load taken by the raft kept decreasing till excavation reaches at half of final excavation depth $(\mathrm{h} / \mathrm{He}=0.5)$. This can be attributed to separation of the raft and the ground because of induced larger ground surface settlement and lesser piled raft settlement. The load carried by the raft reduced to $2 \%$ at excavation stage $\mathrm{h} / \mathrm{He}=0.5$ and after that increased to $4 \%$ on completion of the excavation. 
(d) Owing to constraint of pile lateral movement due to rigid connection with the pile raft, substantial negative bending moment was induced at/near the head of the pile due to excavation. To counter-balance the negative moment at the pile head, a positive bending moment was induced in both piles. The maximum positive bending moment was $200 \mathrm{kNm}$ at $Z / L_{p}=0.67$. Compared the induced bending moment in the pile P1 on completion of the excavation, the pile P2 is subjected smaller bending moment along the length of the pile. Since pile toes are free to move, no any bending moment was induced in both the piles at the toes.

\section{REFERENCES}

[1]. A. Goh, K. Wong, C. Teh, D. Wen, "Pile response adjacent to braced excavation", Journal of Geotechnical and Geoenvironmental Engineering, ASCE, Vol.4, No.129, pp.383-386, 2003

[2]. B. C. B. Hsiung, "A case study on the behaviour of a deep excavation in sand." Computer and Geotechnics, Vol. 36, No. 4, pp. 665-675, 2009

[3]. C. Leung, Y. Chow, R. Shen. "Behavior of pile subject to excavation-induced soil movement." Journal of Geotechnical and Geoenvironmental Engineering, ASCE, Vol. 11, No. 126, pp. 947-954, 2000

[4]. C. Leung, J. Lim, R. Shen, Y. Chow, "Behavior of pile groups subject to excavation-induced soil movement." Journal of Geotechnical and Geoenvironmental Engineering, ASCE, Vol. , No. 129, pp. 58-65, 2003

[5]. C. W. W. Ng, M. Shakeel, J. Wei, S. Lin "Performance of Existing Piled Raft and Pile Group due to Adjacent Multipropped Excavation: 3D Centrifuge and Numerical Modeling". Journal of Geotechnical and Geoenvironmental Engineering, ASCE, Vol. 147, No. 4, pp. 04021012, 2021

[6]. C. W. W. Ng, J. Wei, H. G. Poulos, H. Liu, Han, "Effects of Multipropped Excavation on an Adjacent Floating Pile". Journal of Geotechnical and Geoenvironmental Engineering, ASCE, Vol. 143, No. 7, pp. 04017021, 2017

[7]. C. W. W. Ng, Y. Hong, G. Liu, T. Liu, "Ground deformations and soil-structure interaction of a multi-propped excavation in Shanghai soft clays." Géotechnique, Vol. 62, No. 10, pp. 907-921, 2012

[8]. C. W. W. Ng, T. L. Y. Yau, J. H. M. Li, W. H. Tang, "New failure load criterion for large diameter bored piles in weathered geomaterials." Journal of Geotechnical and Geoenvironmental Engineering, ASCE, Vol. 127, No. 6, pp. 488-498, 2001

[9]. D. Mašín, "A hypoplastic constitutive model for clays." Int. J. Numer. Analyt. Meth. Geomech., Vol. 29, No. 4, pp. 311-336, 2005

[10].D. Mašín, I. Herle, "State boundary surface of a hypoplastic model for clays." Computers and Geotechnics, Vol. 32, No. 6, pp. 400-410, 2005

[11]. D. Ong, C.F. Leung, Y. Chow, "Pile behavior due to excavation-induced soil movement in clay. I: Stable wall."
Journal of Geotechnical and Geoenvironmental Engineering, Vol. 132, No. 1, pp. 36-44, 2006.

[12].D. Ong, C.F. Leung, Y. Chow. "Behavior of pile groups subject to excavation-induced soil movement in very soft clay." Journal of Geotechnical and Geoenvironmental Engineering, Vol. 135, No. 10, pp. 1462-1474, 2009

[13].D. Liyanapathirana, R. Nishanthan, "Influence of deep excavation induced ground movements on adjacent piles." Tunnelling and Underground SpaceTechnology, Vol. 52, pp. 168-181, 2016

[14].R.J. Finno, S.A. Lawrence, N.F. Allawh, I.S. Harahap, "Analysis of performance of pile groups adjacent to deep excavation", Journal of Geotechnical and Geoenvironmental Engineering, ASCE, Vol.6, pp. 934-955, 1991

[15].S.W. Jacobsz, J.R. Standing, R.J. Mair, T. Hahiwara, T. Suiyama, "Centrifuge modelling of tunnelling near driven piles", Soil and Foundations, Vol. 44, No.1, pp. 49-56, 2004 [16]. S.Y. Lam, "Ground movements due to excavation in clay: physical and analytical models". PhD thesis, University of Cambridge, 2010

[17]. H. G. Poulos, L. Chen, "Pile response due to excavation induced lateral soil movement." Journal of Geotechnical and Geoenvironmental Engineering, Vol. 123, No. 2, pp. 94-99, 1997

[18]. M. Korff, R. J. Mair, F. A. Van Tol, "Pile-Soil Interaction and Settlement Effects Induced by Deep Excavations." Journal of Geotechnical and Geoenvironmental Engineering, Vol. 142, No. 8, pp. 040160342016, 2016

[19]. J. H. Atkinson, D. Richardson, S. E. Stallebrass, "Effect of recent stress history on the stiffness of over consolidated soil." Géotechnique, Vol. 40, No. 4, pp. 531-540, 1990

[20]. J. H. Atkinson, G. Sällfors, "Experimental determination of stress-strain-time characteristics in laboratory and in-situ tests." General report. In Proceedings of 10th European Conference on Soil Mechanics and Foundation Engineering, Florence, Italy, Vol.3, pp. 915-956, 1991

[21]. R. Butterfield, "A natural compression law for soils." Géotechnique, Vol. 29, No. 4, pp. 469-480, 1979

[22]. A. Niemunis, I. Herle, "Hypoplastic model for cohesionless soils with elastic strain range." Mech. Cohesive-Frict. Mater., Vol. 2, pp. 279-299, 1997

[23]. P. Mayne, F. Kulhawy, "K0-OCR relationships in soils." Journal of Geotechnical Engineering, ASCE, Vol. 108, No. 6, pp. 851-872, 1982

[24]. L. M. Zhang, A. M. Y. Ng, "Probabilistic limiting tolerable displacements for serviceability limit state design of foundations." Géotechnique, Vol. 55, No. 2, pp. 151-161, 2005

[25]. Wang, LZ, Chen, KX, Hong. Y, Ng, CWW. Effect of consolidation on responses of a single pile subjected to lateral soil movement. Canadian Geotechnical Journal 2015; 52(6): 769-782 